\title{
DIGITAL CITIZENSHIP: SEBAGAI UPAYA MENINGKATKAN KUALITAS PEMBELAJARAN SEJARAH DI ERA GLOBAL
}

\author{
Ahmad Fakhri Hutauruk \\ Pendidikan Sejarah Universitas Simalungun, ahmadfakhrihutauruk@usi.ac.id
}

INFO ARTIKEL
RiwayatArtikel:
Diterima: 03-1 1-2017
Disetujui: 30-12-2017

Kata Kunci:

Digital Citizenship

Pembelajaran Sejarah

\begin{abstract}
ABSTRAK
Abstrak: Pendidikan sejarah di era globalisasi, mendapat tantangan baru dan dituntut kontribusinya agar dapat menumbuhkan kesadaran sejarah peserta didik baik pada posisinya sebagai anggota masyarakat maupun warga negara, serta mempertebal semangat kebangsaan dan rasa cinta tanah air tanpa mengabaikan rasa kebersamaan dalam kehidupan antar bangsa di dunia. Dalam menjawab tantangan tersebut, diperlukan strategi pembelajaran yang baru dengan memanfaatkan kemajuan teknologi, sehingga dapat membantu guru dan peserta didik dalam mengakses informasi sejarah. Penelitian ini bertujuan untuk mengetahui bagaimana implementasi pembelajaran sejarah di era global. Metode penelitian yang digunakan adalah Studi Pustaka (Library Research). Adapun hasil yang diperoleh adalah dengan memanfaatkan kemajuan teknologi, dapat membantu guru dan peserta didik dalam mengakses informasi sejarah. Hal ini dikarenakan kajian sejarah bersifat dinamis, dan akan terus berkembang sesuai dengan perkembangan zaman. Dengan menerapkan konsep "Digital Citizenship" dalam proses pembelajaran sejarah diharapkan dapat meningkatkan kualitas mutu pembelajaran sejarah di sekolah.

Abstract: Education history in the era of globalization, a new challenge and claimed its contribution in order to foster awareness of learners' history both in its position as a member of society and citizens, and strengthen the spirit of nationalism and love of the homeland without ignoring the sense of togetherness in life among nations in the world. In response to these challenges, new learning strategies are needed by utilizing technological progress, so as to help teachers and learners access historical information. This study aims to find out how the implementation of learning history in the global era. The research method used is Library Studies (Library Research). The results obtained is to take advantage of technological progress, can help teachers and learners in accessing historical information. This is because the study of history is dynamic, and will continue to grow in accordance with the times. By applying the concept of "Digital Citizenship" in the learning process of history is expected to improve the quality of learning history in school.
\end{abstract}

Seperti yang dikemukakan oleh Herbert Spencer

\section{A. LATAR BELAKANG}

Pendidikan merupakan proses membantu dan memfasilitasi peserta didik untuk mengembangkan seluruh potensi yang dimiliki agar berkembang sesuai dengan tugas perkembangannya. Pendidikan merupakan proses perubahan tingkah laku peserta didik agar menjadi manusia dewasa yang mampu hidup mandiri sebagai anggota masyarakat dalam lingkungan sekitar dimana individu itu berada. Pendidikan tidak hanya sekedar mengembangkan intelektual semata, akan tetapi lebih menekankan pada proses pembinaan kepribadian peserta didik secara menyeluruh sehingga dapat menjadi dewasa dan mengetahui status serta perannya di masyarakat. (dalam Nasution, 1983:34) bahwa tujuan pendidikan adalah :

1. Self Preservation: Manusia harus dapat menjaga kelangsungan hidupnya dengan hidup sehat, mencegahnya penyakit, hidup teratur $\mathrm{dsb}$

2. Securing The Necessites of Life: ia harus sanggup mencari nafkahnya dan memenuhi kebutuhan hidupnya dengan melakukan suatu pekerjaan

3. Rearing A Family: ia harus menjadi ibu atau bapak yang sanggup bertanggungjawab atas pendidikan anaknya dan kesejahteraan keluarganya.

4. Maintaining Proper Social And Political Relationship: setiap manusia adalah makhluk sosial yang hidup dalam lingkungan masyarakat dan negara. Oleh karena itu ia harus pandai bergaul, rela 
bekerjasama dengan orang lain dan memenuhi kewajibannya sebagai warganegara

5. Enjoying Leisure Time: Ia harus sanggup memanfaatkan waktu senggangnya dengan memilih kegiatan-kegiatan dan kegairahan hidup.

Dengan memberikan pendidikan yang baik, setiap orang akan mengetahui hak dan tanggung jawabnya sebagai individu, anggota dimasyarakat serta sebagai makhluk Tuhan. Dengan kata lain, pendidikan merupakan hak fundamental yang harus dipenuhi bagi setiap masyarakat dalam kehidupannya. Tujuan dari pendidikan adalah membantu peserta didik untuk mengembangkan seluruh potensi yang terdapat dalam dirinya baik secara rasionalitas, moralitas, sosialitas maupun spiritualitasnya. Untuk menjadi seseorang dengan kepribadian yang paripurna atau menyeluruh maka diperlukan pendidikan ditengah perubahan zaman yang serba cepat. Hal ini dikarenakan, pendidikan terus berkembang sejalan dengan perubahan zaman. Dengan demikian, lambat laun pendidikan menjadi lebih modern karena kemajuan IPTEK yang sangat pesat.

Pendidikan sejarah yang diajarkan di sekolah menjadi salah satu alternatif untuk mencapai tujuan yang telah dikemukakan di atas. Seperti yang dijelaskan oleh Isjoni (2007:40) bahwa "Pendidikan sejarah di sekolah bertujuan membangun kepribadian dan sikap mental anak didik, membangkitkan keinsyafan akan suatu dimensi fundamental dalam eksistensi umat manusia (kontinuitas gerakan dan peralihan terus menerus dari yang lalu ke arah masa depan), mengantarkan manusia kepada nilainilai kejujuran dan kebijaksanaan pada anak didik, dan menanamkan cinta bangsa dan sikap kemanusian".

Hal ini dikarenakan, dalam konteks kehidupan berbangsa dan bernegara, pembelajaran sejarah sebenarnya memiliki peran yang sangat strategis. Hal ini karena pendidikan sejarah adalah mata pelajaran yang cukup tua dalam kurikulum pendidikan di Indonesia (Hasan, 2012:60). Pembelajaran sejarah sebagai subsistem dari sistem kegiatan pendidikan, merupakan sarana yang efektif untuk meningkatkan integritas dan kepribadian bangsa melalui proses belajar mengajar. Keberhasilan ini akan ditopang oleh berbagai komponen, termasuk kemampuan dalam menerapkan metode pembelajaran yang efektif dan efisien. Sistem kegiatan pendidikan dan pembelajaran adalah sistem kemasyarakatan yang kompleks, diletakkan sebagai suatu usaha bersama untuk memenuhi kebutuhan pendidikan dalam rangka untuk membangun dan mengembangkan diri (Bela H. Banathy dalam Aman, 2009:45).

Di era globalisasi, pendidikan sejarah cukup mengalami tantangan besar dan saat ini dituntut perannya agar dapat menumbuhkan kesadaran sejarah, baik pada posisinya sebagai anggota masyarakat maupun warga negara, serta mempertebal semangat kebangsaan dan rasa cinta tanah air tanpa mengabaikan rasa kebersamaan dalam kehidupan antar bangsa di dunia.

Untuk menghadapi tantangan tersebut perlu dilakukan suatu pendekatan "Cross-Curricular" dalam proses pembelajaran sejarah. sebagaimana yang dikemukan oleh Winataputra dan Budimansyah (2012:6) bahwa "Pendekatan 'Cross-Curricular', Citizenship Education tidaklah secara khusus sebagai suatu mata pelajaran atau suatu topik, melainkan secara sistemik dimasukkan ke dalam keseluruhan tatanan kurikulum dengan memasukkanya kedalam mata pelajaran yang ada. Dengan demikian, guru sejarah akan menyelipkan makna dari Citizenship Education dalam proses pembelajaran, sehingga dapat menjawab tantangan global.

Berdasarkan latar belakang yang telah dikemukakan diatas, maka peneliti tertarik untuk meneliti lebih lanjut. Adapaun masalah dalam tulisan ini dapat dirumuskan dalam bentuk pertanyaan pokok sebagai berikut: Bagaimana implementasi pembelajaran sejarah di era global?

\section{B. METODE PENELITIAN}

Penelitian ini berkaitan dengan penelitian sejarah, sebagaimana yang dijelaskan oleh Garraghan dalam Abdurrahman (2007:53) mendefinisikan metode penelitian sejarah adalah seperangkat aturan dan sistem sistematis yang mengumpulkan sumber-sumber sejarah secara efektif, menilainya secara kritis, dan mengajukan sintesis dari hasil-hasil yang dicapai dalam bentuk tertulis. Dengan demikian dalam penelitian ini, peneliti menggunakan metode penelitian studi pustaka (Library Research). 
Adapun teknik analisis data menggunakan analisis model interaktif. Karena dianggap lebih tepat untuk memenuhi persyaratan dalam melakukan analisis data. Analisis interaktif terdiri atas tiga alur kegiatan yang terjadi secara bersamaan, yaitu: reduksi data, penyajian data dan penarikan simpulan/verifikasi (Miles dan Huberman, 1992:16).

\section{HASIL DAN PEMBAHASAN}

Keadaan masyarakat saat ini yang kurang siap menghadapi perubahan sesungguhnya merupakan sebuah wujud ketidaksiapan mental dari generasi kita. Kesiapan mental ini sebenarnya dapat dikembangkan melalui pemahaman makna dinamika sejarah yang benar. Dengan kata lain akar sebenarnya dari permasalahan itu adalah tidak lain merupakan kegagalan atau ketidaksiapan kita mengembangkan kewaspadaan sejarah (historical awareness) dalam menghadapi setiap kejutan yang dibawa oleh setiap tentangan jaman, akibat urang dipahaminya sejarah secara benar. Belajar sejarah merupakan wahana pendidikan siswa agar mampu menemukan jatidiri pribadi, masyarakat dan bangsanya melalui belajar sejarah siswa dibimbing untuk menyadari fungsinya dalam masyarakat dan akhirnya diharapkan menjadi manusia yang mau dan biasa melakukan aktivitas yang bermanfaat di dalam kehidupan sehari-hari dan berpartisipasi dalam membangun masyarakat yang demokratis (Wiriatmadja, 2002:10).

Hal ini terlihat jelas, karena pada era global telah melahirkan beragam kebudayaan global. Hal tersebut tidak dapat dibendung, namun dapat dikurangi dampaknya dengan melakukan penyaringan (filtering). Dapat kita lihat sebagai contoh dari peristiwa yang sering terjadi di kalangan peserta didik seperti penyalahgunaan narkoba. Ini merupakan fenomena yang sering dijumpai dikalangan peserta didik yang merupakan bahaya besar bagi generasi muda. Oleh karena itu, dibutuhkan pondasi yang kuat untuk meredam hal tersebut yakni identitas diri. Dengan identitas, sebagai bangsa yang memiliki norma-norma sosial, identitas tersebut dapat membentengi generasi muda dari pengaruh negatif dari globalisasi.

Pembelajaran sejarah sangat diperlukan karena dapat membangkitkan kesadaran empatik (emphatic awareness) dikalangan peserta didik, yaitu sikap empati dan toleransi terhadap orang lain. Juga disertai dengan kemampuan mental untuk berimajinasi dan kreativitas, jika sejarah dipahami dengan benar oleh peserta didik. Pengajaran sejarah nasional di sekolah, bagaimanapun akan memperkenalkan peserta didik kepada pengalaman kolektif dan masa lalu bangsanya. Pengajaran ini juga membangkitkan kesadaran dalam kaitannya dengan kehidupan bersama dalam komunitas yang lebih besar, sehingga tumbuh kesadaran kolektif dalam memiliki kebersamaan dalam sejarah.Proses pengenalan diri inilah yang merupakan titik awal dari timbulnya rasa harga diri, kebersamaan, dan keterikatan (sense of solidarity), rasa keterpautan dan memiliki (sense of belonging) kemudian rasa bangga (sense of pride) terhadap bangsa dan tanah air (Wiriatmadja, 2002:156).

Sebagaimana yang telah tercantum dalam dokumen kurikulum sejarah tahun 2004 bahwa "Fungsi pengajaran sejarah adalah untuk menyadarkan siswa akan adanya proses perubahan dan perkembangan masyarakat dalam dimensi waktu dan untuk membangun perspektif serta kesadaran sejarah dalam menentukan, memahami, dan menjelaskan jatidiri bangsa di masa lalu, masa kini dan masa depan di tengah-tengah perubahan dunia".

Selanjutnya, Capra (dalam Wiriatmadja, 2002:29) menaruh harapan yang begitu tinggi pada sejarah, menurutnya sejarah termasuk dalam disiplin ilmu yang menyajikan etika, moral, kebijaksanaan, nilai-nilai spiritual dan kultural karena kajiannya yang bersifat memberi pedoman kepada keseimbangan hidup, harmoni dalam nilai-nilai keteladanan dalam keberhasilan dan kegagalan dan cermin pengalaman kolektif yang dapat menjadi kompas untuk kehidupan masa depan.

Djamarah dan Hamalik (dalam Wiyanarti, t.t:12) mengemukakan ada lima (5) kegiatan utama dalam merancang strategi pembelajaran sejarah, yakni:

1. Mengidentifikasi kemampuan kondisi awal peserta didik, serta menetapkan spesifikasi dan kualifikasi perubahan tingkah laku dan kepribadian peserta didik sebagaimana diharapkan.

2. Memilih sistem pendekatan pembelajaran sejarah berdasarkan aspirasi dan pandangan hidup masyarakat. 
3. Memilih dan menetapkan prosedur, metode, dan teknik mengajar sejarah yang dianggap paling cocok dan efektif sehingga dapat dijadikan pegangan oleh guru dalam memunaikan tugasnya.

4. Menetapkan norma-norma dan batas minimal keberhasilan atau kriteria serta standar keberhasilan agar dapat dijadikan pedoman oleh guru dalam melakukan.

5. Evaluasi baik proses maupun hasil belajar sejarah, yang selanjutnya akan dijadikan umpan balik untuk penyempurnaan sistem pembelajaran secara keseluruhan.

Oleh karena itu, proses pembelajaran sejarah diera digital ini perlu menggagas konsep yang baru tanpa menghilangkan esensi dari sejarah itu sendiri. Selain itu, gagasan tersebut juga memudahkan guru dan peserta didik dalam memahami sejarah di zaman yang penuh tantangan ini.

Dengan mengedepankan konsep "Digital Citizenship" dalam proses pembelajaran sejarah. Seperti yang dikemukakan oleh Mossberger (2008) bahwa Digital citizens are those who use technology frequently, who use technology for political information to fulfill their civic duty, and who use technology at work for economic gain".

Warga negara digital adalah mereka yang sering menggunakan teknologi, mereka yang mengunakan teknologi untuk informasi teknologi untuk memenuhi kewajiban warga negara dan mereka yang dalam pekerjaan untuk tujuan ekonomi.

Digital Citizenship is a concept which helps teachers, technology leaders and parents to understand what students/young people/technology users should know to use technology appropriately. Digiwtal Citizenship is more than just a teaching tool; it is a way to prepare students/technology users for a society full of technology (Rible, 2013).

Kewarganegaraan digital merupakan sebuah konsep yang membantu guru, Tokoh teknologi, Orang tua untuk memahami tentang murid// masyarakat muda/ pengguna teknologi mengetahui untuk menggunakan teknologi sewajarnya. Kewarganegaraan lebih dari hanya alat untuk mengajar, tetapi merupakan cara untuk mempersiapkan siswa/pengguna teknologi untuk sebuah masyarakat yang penuh dengan teknologi.

Karena setiap individu dapat dipastikan tidak akan pernah lepas dari ketergantungan kemajuan teknologi perlu kiranya diketahui siapa saja yang dapat dikatakan sebagai warga digital, yaitu:

1. Today's young people are navigating a new digital culture in which the rules and social norms are sometimes unclear. They must learn about digital citizenship and develop a sense of ownership and personal responsibility to make good, ethical decisions in the online world

2. The online world presents great opportunities for young people, but it is not without risks. We can mitigate some of those risks by helping young people develop a strong sense of digital citizenship.

3. Rather than relying solely on protective measures, an approach to online safety that includes digital citizenship will help young people safely interact in the online world. Teaching them about digital literacy and digital ethics and etiquette is no longer merely an option; it is an imperative. (Microsoft. Fostering Digital Citizenship)

1. Saat ini masyarakat muda berada pada sebuah budaya digital yang baru yang mana peraturan dan norma sosial terkadang belum jelas. Mereka harus belajar tentang kewarganegaraan digital dan mengembangkan sebuah rasa kepemilikan dan tanggung jawab personal untuk menciptakan kebaikan, keputusan etis dalam dunia jaringan

2. Dunia jaringan memberikan kesempatan yang besar kepada masyarakat muda, tetapi bukan tanpa resiko. Kita dapat mengurangi beberpa resiko terbut dengan menolong masyarakat muda mengembangkan sebuah rasa kewarganegaraan digital.

3. Daripada menyandarkan hanya pada tindakan protektif, sebuah pendekatan untuk keamanan dalam jaringan bahwa termasuk kewarganegaraan digital dapat menolong masyarakat muda interkasi yang aman dalam dunia jaringan. Mengajari mereka tentang literasi digital dan etika digital serta tata cara hal ini tidak hanya sebuah pilihan melulu, tetapi tidak bisa tidak.

Berdasarkan karakteristik warga digital yang telah dikemukakan diatas dan didukung dengan kemajuan teknologi yang pesat, maka perlu diterapkan konsep "Kewarganegaraan Digital" dalam proses pembelajaran sejarah agar kualitas pembelajaran sejarah di sekolahsekolah akan semakin meningkat. Hal ini dikarenakan, 
seluruh komponen pendidikan ikut terlibat dalam kegitan tersebut baik orangtua, maupun guru memantau perkembangan peserta didik di era digital.

Seperti yang dikemukakan oleh Aman (2009:53) berpendapat bahwa indikator kualitas pembelajaran untuk kualitas pembelajaran sejarah direduksi menjadi 5 indikator, yang dianggap memiliki peranan cukup besar dalam menentukan kualitas pembelajaran. Kelima indikator tersebut adalah: (1) kinerja guru dalam kegiatan belajar mengajar di kelas, (2) sarana pembelajaran sejarah, (3) suasana pembelajaran, (4) sikap positif-kritis siswa, dan (5) motivasi belajar siswa.

Dengan menerapkan konsep "Digital Citizenship" kelima indikator yang telah disebutkan di atas dapat tercapai dengan mudah. Hal ini dikarenakan, dalam setiap proses pembelajaran menggunakan metode dan model up to date sehingga proses pembelajaran sejarah lebih menyenangkan dan mampu mengatasi tantangan yang ada di era digital ini. Karena teknologi informasi memiliki pengaruh besar dalam kehidupan manusia. Dalam proses pembelajaran sejarah tidak seutuhnya materi harus diperoleh dari guru semata, peserta didik juga harus berperan aktif dalam mencari informasi untuk memenuhi kebutuhan intelektualnya di bidang sejarah.

Dengan memanfaat kemajuan teknologi maka informasi akan semakin mudah diperoleh dan peserta didik dapat mengakses informasi tersebut dari mana dan kapan saja.

Hal senada juga dikemukakan oleh (Kalidjernih, 2011:67) bahwa Teknologi informasi telah mempengaruhi cara-cara manusia berpikir dan beraktivitas tanpa melihat latar belakang ras, gender, usia, status dan keyakinan". Dengan demikian Kemajuan bidang TIK menjadi sebuah isu kajian yang sangat menarik dan aktual dalam pendidikan sejarah. Hal ini dikerenakan, warga negara saat ini tidak hanya mudah mendapat informasi tetapi juga sebagai produsen informasi. Maksudnya disini adalah peserta didik dan guru akan saling berbagi informasi mengenai materi sejarah karena model pembelajaran yang diterapkan sudah lebih modern dari sebelumnya. Pemanfaatan teknologi informasi meningkatkan kualitas mutu dalam proses pembelajaran sejarah.
Tidak dapat dipungkiri bahwa teknologi informasi merupakan lokomotif yang dahsyat dalam mendorong transformasi sosial di seluruh dunia dalam beberapa dasawarsa terakhir. Kebanyakan dari proses perubahan ini didasarkan kepada produksi informasi (Kalidjernih 2011:67).

\section{SIMPULAN DAN SARAN}

Pendidikan sejarah di era globalisasi, mendapat tantangan baru dan dituntut kontribusinya agar dapat menumbuhkan kesadaran sejarah baik pada posisinya sebagai anggota masyarakat maupun warga negara, serta mempertebal semangat kebangsaan dan rasa cinta tanah air tanpa mengabaikan rasa kebersamaan dalam kehidupan antar bangsa di dunia. Dengan demikian, untuk menjawab tantangan tersebut diperlukan suatu strategi baru yang diaplikasikan dalam proses pembelajaran sejarah.

Dengan memanfaatkan kemajuan teknologi, dapat membantu guru dan peserta didik dalam mengakses informasi sejarah. Hal ini dikarenakan kajian sejarah bersifat dinamis, dan akan terus berkembang sesuai dengan perkembangan zaman. Dengan menerapkan konsep "Digital Citizenship" dalam proses pembelajaran sejarah diharapkan dapat meningkatkan kualitas mutu pembelajaran sejarah di sekolah.

\section{DAFTAR RUJUKAN}

Abdurrahman, Dudung. 2007. Metodologi Penelitian Sejarah. Yogyakarta: Ar-Ruzz Media

Aman. (2009). Evaluasi Pembelajaran Sejarah. Yogyakarta: Diktat Jurusan Pendidikan Sejarah Fakultas Ilmu Sosial dan Ekonomi Universitas Negeri Yogyakarta. Sumber tersedia di:

http://staff.uny.ac.idsystemfilespendidikanDr.\%2 0Aman,\%20M.Pd.A-5\%20DIKTAT.pdf (diunduh 8 ذanuari 2018)

Hasan, S. Hamid. (2012). Pendidikan Sejarah Indonesia. Bandung: Rizqi Press

Isjoni. (2007). Pembelajaran Sejarah pada Satuan Pendidikan. Bandung: Alfabeta 
Kalidjernih, Freedy K. (2011). Puspa Ragam, Konseo dan Isu Kewarganegaraan. Bandung: Widya Asara Press; Edisi ketiga.

Karen Mossberger, Caroline J. Tolbert, and Ramona S. McNeal. (2008). Digital Citizenship. London, England: The MIT Press Cambridge, Massachusetts

Microsoft. Fostering Digital Citizenship. Sumber tersedia di: http://www.oaesv.org/wpcontent/uploads/2013/02/Fostering Digital Citize nship.pdf(diunduh 8 Januari 2018)

Miles, Mathew B \& Huberman, A. Michael. 1992. Analisis Data Kualitatif. Jakarta: Universitas Indonesia Press

Mike Ribble in Fostering Digital Citizenship. Sumber tersedia di: http://www.oaesv.org/wpcontent/uploads/2013/0 2/Fostering Digital Citizenship.pdf (diunduh 1 Maret 2017)

Nasution. (1983). Asas-Asas Kurikulum. Bandung: Jammars Winataputra, U S dan Budimansyah, D.. (2012). Pendidikan Kewarganegaraan dalam Perspektif Internasional (konteks, teori dan Profil Pembelajaran. Bandung: Widya Aksara Press.

Wiriaatmadja, Rochiati. (2002). Pendidikan Sejarah Indonesia, Perspektif Lokal Nasional dan Global. Bandung: Historia Utama Press

Wiyanarti, Erlina. (t.t). Model Pembelajaran Konstektual dalam Pengembangan Pembelajaran Sejarah. Pdf Sumber tersedia di: http://file.upi.eduDirektoriFPIPSJUR. PEND. SEJAR $\underline{\mathrm{AH} 196207181986012-}$ ERLINA WIJANARTICTL DLM PMBLRAN SEJARAH .pdf (Diunduh 8 Januari 2018) 